\title{
Students as library advocates The library student advisory board at Pennsylvania State-Schuylkill
}

$\mathbf{S}$ udents are excellent library advocates to heir peers when they are well informed about the library's collections and services and have a clear, consistent message to share. The formation of a Library Student Advisory Board (LSAB) as a campus student club at Pennsylvania State University's (PSU) Schuylkill Campus has helped spread a positive message about our library to the student body and has improved our library collections and services.

At many institutions, academic librarians meet with students a few times a year to get feedback on library policies or to hear issues raised by students campuswide. Typically librarians meet with an individual representative of the student government or a small group of students interested in making a plea for later hours or a café in the library. ${ }^{1}$ The PSU-Schuylkill LSAB is quite different, and it is a type of student group that could be successful on a variety of college and university campuses. Enthusiastic students, led by a passionate club advisor, created the LSAB to help spread the word that the library is a wonderful place to conduct research, take advantage of librarian expertise, use personal laptops in a wireless environment, study, have club meetings, or just relax.

LSAB activities include locating and raising funds to purchase materials of student choice to donate to the library, developing ideas for creating a better student experience at the library, and acting as peer advocates of the library to encourage student use. Club members promote use of the library to friends, faculty, and other community members any time an opportunity arises. Additionally, the student group serves to provide feedback on issues such as marketing to the local student population and changes to the interface of the university-wide online catalog. In this sense, our group is more like a public library's "friends group."

\section{Establishing a student group on campus}

In a student-centered environment, the campus library can serve to meet the educational needs of its students, while also addressing their personal needs. This is especially true in a small campus setting with limited alternatives. LSAB was organized in fall 2003, when the Ciletti Memorial Library staff and administration recognized a need to increase student usage and to understand student thinking on local policies, services, and collections. Like many campus libraries, we fear declining use of the brick-and-mortar library building with so many of our resources being available electronically and with high-speed Internet use from home continuing to rise.

Though our library has recovered from a decline in usage in the late ' 90 s and is back to the usage levels recorded ten years ago, tech savvy students make use of our software-laden computers and audiovisual equipment just as much as our traditional group meeting and quiet study spaces. Our

Amy Deuink is reference and instruction librarian, e-mail: ald120@psu.edu, and Marianne Seiler is acquisitions and serials coordinator and LSAB advisor, e-mail: mxs84@psu.edu, at Pennsylvania State University-Schuylkill

๑ 2006 Amy Deuink and Marianne Seiler 
library is gradually moving towards the notion of an information commons, and students are making their needs known by where they choose to work while they are here. Club members are enthusiastic about showing the rest of their peers the great variety of resources the library has to offer.

The idea for LSAB for the PSU-Schuylkill Ciletti Memorial Library grew from conversations among library administration and staff, but staff assistant Marianne Seiler took the lead role in making the idea into a reality and would become the group's advisor. Seiler was deeply committed to getting students excited about libraries and showing them what libraries have to offer.

She drew on her local social contacts to establish the core group of student members needed to form a new club. The mother of a high school football player, she recruited members of her son's team who would be matriculating to PSU-Schuylkill in fall 2003, as well as their girlfriends and sisters. These students already knew each other and had successfully worked together on the field and in the classroom to achieve a common goal. The group's first meeting consisted of some jovial play and a lot of serious brainstorming. Echoing the stereotype, these students admitted they were not regular library users. Frankly, this group was exactly the type of students library administration and staff were trying to draw into the library.

While brainstorming ideas for group initiatives they asked a lot of great questions, such as "Why doesn't the library have more popular magazines for men?" and "Why doesn't the library have more popular videos for students to watch on weekends?" After our first club meeting everything seemed to fall into place-the students knew what they wanted and were eager to share their ideas and opinions. Once the group was officially established, we were able register new members at the campus Activities Fair. We also gained new members by recruiting library student workers, members bringing their friends to meetings, and the reputation we earned as a fun and exciting club-all contributing to increased diversification of the club. We discovered that unlike some campus clubs, LSAB attracts both residential and commuter students.

\section{Input into collection development}

PSU-Schuylkill is a small campus of approximately 969 residential and commuter students in the Appalachian Mountains of East Central Pennsylvania. As one campus in a large university network, many universitywide systems, policies, and procedures are standardized across the university. However, collection development is the greatest area of local discretion; we develop our collection to meet the primary research needs of students at our campus. Club members quickly learned the library's collection was the area in which they could have the greatest effect on the greatest number of students.

Academic libraries routinely seek collection development input from the faculty and entertain requests from students, but our LSAB gives the student body an opportunity to obtain video and popular book titles, largely for entertainment, that are often low on the priority list for an academic library's collection budget. Club members place suggestion boxes strategically around campus and rank suggested titles by popularity. They purchase as many of the titles as possible by taking advantage of bookstore discounts and buying previously viewed videos from rental stores. As an example of the effect these acquisitions have had on student life, the 41 video titles the club purchased during 2003-04 have circulated 256 times! As with any donation, library administration approves all offered materials before adding them to the collections.

\section{Creating awareness through activities}

By the end of the first year, LSAB had 19 members. The club sold candles and embroidered campus scarves, resulting in two very successful fundraisers. We were granted $\$ 500$ from the Student Activity Fund (students pay a mandatory activity fee upon enrollment) to 
buy DVDs, which were added to our library collection for our students, faculty, and local community to check out and enjoy. Our club designed and displayed READ posters featuring campus faculty holding their published works to help raise awareness during National Library Week in 2004. This initiative led to an article about the club in the Pennsylvania Library Association's Bulletin. In addition, the club successfully lobbied the campus Business Services Office and library administration to add a soda machine in the library's café area, which already housed snack and coffee vending machines.

An advantage of being a campus student club is being able to solicit new members at the campus activities fair at the beginning of each semester, along with approximately 20 other student clubs. As a result, the club grew to 26 members in its second year.

In 2004-05, LSAB had two more successful fundraisers, a car wash and a sale of campus apparel (embroidered t-shirts, blankets, and scarves), which earned \$1,189.30 for the club. In addition, we received a total of $\$ 2,000$ from the campus Student Government Association (SGA) and another $\$ 500$ from the Student Activity Fund. Due in part to LSAB's enthusiastic and outgoing club members, in 2004-05 library usage was up by 9 percent, or 906 additional students entering the library. This figure is close to our campus' entire student population! And, as a result of increasing student awareness, other clubs have decided to start holding their meetings in the library.

Achievements during the 2004-05 school year included:

- purchasing 60 bestsellers and 100 recently released DVDs with SGA and Student Activity funds;

- highlighting library materials with a new theme each month in a prominently placed library exhibit case-themes include Black history, Irish history, art, bestsellers, summer reading, etc.;

- development of a "menu book" for students wishing to order food from offcampus restaurants;

- acting as library volunteers when additional staff are needed;

- successful solicitation of campus administration for a new public printer when the old printer started to frequently break down;

- purchase of a color printer to create flyers and other promotional materials for club use; and

- entry in a contest for which club members created a unique display of Franklin D.

\section{How to develop a successful student advisory group}

Based on two years of experience with this club, the authors recommend the following keys to the development of a successful student advisory group:

- Recruit new members throughout the year. Your undergraduates are only here a short time, so your turnover rate can be quite substantial!

- Be available and responsive to the students, in person and in the virtual world. Once your members sign up, have the advisor stay in constant contact with them during the school semesters and throughout the summer.
- Conduct monthly meetings to keep the ideas and actions flowing and to gain continuous feedback.This leads to ongoing interest on the part of the students and retention of group members from year-to-year.

- Listen to students' ideas and suggestions and treat them with respect.

- Take actions on ideas proposed by club members.

- Show enthusiasm for the club and the library by letting your students be creative and not afraid to express their ideas.

- Serving food at meetings always helps! 
Roosevelt materials to honor his memory, with the possibility of winning a grant of up to $\$ 1,000$.

An achievement of which LSAB was particularly proud was its participation in the celebration of the library building's tenth anniversary celebration in April 2005. LSAB members created a special display of books purchased for the library through club funds and acted as information stewards for visitors on the day of the event. The club president spoke during the day's ceremony as a representative of the student body. A small grove of trees planted to commemorate the anniversary includes a maple donated by LSAB. And, the winner of the Information Contest held during the anniversary celebration was very pleased to receive an embroidered stadium blanket donated by the club. The information contest, quizzing participants on campus and community history and trivia, was advertised on campus electronic discussion lists and in the local newspaper.

Additionally, a member of LSAB now regularly attends meetings as a voting member of the Faculty Senate Libraries Committee. This committee serves in a consultative and advisory capacity to library administration through the Senate. In the past, the committee has had difficulty attracting an interested student as a member; with the formation of LSAB, a consistent student voice is now present on the committee.

In the upcoming year, LSAB is planning to hold another car wash fundraiser and would like to purchase an additional television and VHS/DVD player for the library. The LSAB is also becoming a partner with the library for its Open House event. The Open House is part of the campus' First-Year Seminar Support Program-targeting first-year students, but open to all. It is an opportunity for students to become familiar with the library building, services, and staff in a fun way in order to reduce library anxiety.

\section{Conclusion}

Students, as library advocates, are a powerful marketing tool. Having a LSAB on campus allows the students to have a voice. This voice provides students with the opportunity to present ideas to enhance the library and make it more student-friendly. Students using the library are more aware of what they need for courses and for recreational needs.

The club meetings help the students, staff, and faculty resolve issues and share concerns so that we may achieve our goal of increasing awareness of our library and what we have to offer them. LSAB is also one of very few campus clubs that benefit the entire campus population with their contributions. Outgoing LSAB President Patrick Troutman sums up the group in this way:

LSAB has given me a chance to strengthen my leadership skills, meet new people, and learn about the library's many processes. The 'library club,' as I have come to call it, is something I feel Penn State can be very proud to have. It allows a high level of communication between students and the campus faculty and staff and I believe that it is groundbreaking. Though I leave my position as President at the end of the semester, I will forever be part of the club, and this club will forever be a part of me. ${ }^{2}$

\section{Notes}

1. Candace R. Benefiel, Wendi Arant, and Elaine Gass, "A new dialogue: A student advisory committee in an academic library," Journal of Academic Librarianship 25 (March 1999): 111-13.

ASU Libraries, Arizona State University, "Library Student Advisory Committee," Arizona Board of Regents, www.asu.edu/lib/ stuadvis/ (accessed August 3, 2005).

Gelman Library, "Gelman Library Student Liaison," George Washington University, www.gwu.edu/gelman/library/liaison (accessed on August 3, 2005).

Eckles Library, "Eckles Library Student Advisory Board," George Washington University, www.gwu.edu/gelman/eckles/ board.html (accessed August 3, 2005).

2. Personal communication. $\boldsymbol{z}$ 